\title{
Moving Center Stage: patients claim their role in healthcare
}

\author{
Anke-Peggy Holtorf ${ }^{1,2}$, Neil Bertelsen ${ }^{2,3}$ \\ Health Outcomes Strategies $\mathrm{GmbH}$, Basel, Switzerland \\ HTAi Patient and Citizen Involvement Group \\ Neil Bertelsen Consulting, Berlin, Germany
}

Working in the world of healthcare, the last few years have seemed like the beginning of a revolution, and this revolution has a rallying cry: Patient Centricity. Suddenly, it seems that all the actors in the healthcare system have woken up to the fact that patients deserve to be central to the healthcare and technological decisions that affect them. Wouldn't you think that patients have been in the centre of medicines since Hypocrates of Cos stated almost 2500 years ago that their diseases have natural causes and that the course of the disease can be influenced by medicines? However, for many hundred years, the science of developing medicines has been driven by an authoritative approach to experimentation with patients as subjects rather than genuine participants in these technological developments.

Even quite recently, many medicines were developed purely through the championship of one expert, with the science at the centre of the innovation and with limited consideration of the needs and wants of the patients, and thus, the overall outcome. Only after disastrous adverse events caused by some therapies marketed in the nineteen-fifties such as thalomide or animal cell therapy, regulatory requirements were introduced which made safety data, risk evaluation and pharmacovigilance processes an important part of medicines development [1]. In addition, prescription laws were introduced or intensified to protect patients from uncontrolled overuse. It became important for the healthcare system and pharmaceutical companies to better understand prescribers' behaviours and needs. To prevent failures in the market, interactions with prescribers began to happen throughout the clinical development - but where was the patient in this?

Perhaps we can trace the moment when patients first started to fight against a system which locked them out of the decision process to October 11, 1988 when a large group of activists laid siege to the FDA offices in Washington DC. They fought against the mechanisms that were being used to approve new medicines against HIV. This rise of activism was fuelled by anger at the seeming lack of progress in releasing the new antivirals to patients in need, and fuelled by the lack of a patient voice in the decision-making processes [2].

Although this action in 1988 should have sounded an alarm for including the patients in decisions, scientists, clinicians and decision makers were already pursuing another course. The principle of Evidence Based Medicine (EBM) had become the vehicle by which patients would truly benefit. Only evidence with the highest epistemological strength (i.e., coming from meta-analyses, systematic reviews, and randomized controlled trials) should yield strong recommendations in guidelines [3]. Also regulatory authorities strengthened their evidence requirements from the viewpoint of EBM for market authorization. Hence, pharmaceutical companies adapted their development process to yield the quality data appropriate for supporting product authorization and adoption to standard practice. However, this push for better evidence still left out the patient. It was the scientists and experts who determined which evidence to use, often resulting in measures that meant little to the daily life of a person with a disease.

The principles of EBM were adopted by a new group of stakeholders in the 1990s, Health Technology Assessment bodies. EBM provided the foundation for assessing the value of new pharmaceuticals, but, in contrast to the traditional clinical endpoints which often were surrogate markers for an expected health impact, HTA bodies began asking for evidence that demonstrated actual outcomes relevant to patients.

Because HTA decision-makers had to recommend priorities in listing or reimburse-
Corresponding author Anke-Peggy Holtorf, PhD, MBA anke.holtorf@health-os.com

\section{Disclosure}

The authos have no conflicts of interest to declare. 
ment, they expected to see scientifically robust outcomes data for the new product in comparison to the current standard of care. Furthermore, HTA processes embraced also the questions for economic, ethical and legal consequences [4].

Being faced with product evaluations from the perspective of a payer or a healthcare system, the pharmaceutical industry swiftly established processes which allowed early challenge of the development plans from this viewpoint and appropriate improvements to better meet HTA needs [5].

If the HIV community's battle with the FDA was a plea for a more patient-centred regulatory system, then the focus on patient relevant outcomes at the HTA level raised the debate to one about patient values. In retrospect, we see this as the next big step for patients in moving to the centre.

As HTA bodies were grappling with the concept of patient relevance and what this meant for the evidence that they would require, patients themselves were becoming much more connected, informed and assertive. Today, patients and caregivers network, collaborate, and have become organized. They have learnt how decisions are made. Patient organizations have fought against decisions which were made without them but which, in their view, have an impact on their health. Therefore, regulatory and HTA agencies have started to include patients or citizens perspectives into their decisions and in some cases as partners in their assessment of new technologies [6].

A few stumbling blocks have appeared along the way towards participatory decision making or Patient and Public Involvement (PPI), one of the most important being the com- munication between the different stakeholders (clinical, researchers, patients, citizens). Industry players have struggled to determine the best way to engage patients and many barriers exist, but there is a new determination to overcome them [7]. A range of trainings for patients or citizens have been developed to give them the base understanding of good research and clinical practices as well as decision making in healthcare. Online trainings and guidance (e.g., EULAR [8]) or certification courses (e.g. EUPATI [9]) are available for those patients who want to become more engaged in research and healthcare decisions. Now it finally is time for the pharmaceutical research and development community to conduct their research with the patients as partners in this scientific journey. The concept of patient centricity needs to become action, not just words. To become truly patient centric the patient perspective needs to percolate the innovation chain throughout research and development.

What can go wrong without involving patients actively? There are many examples of therapeutics which were developed with good intentions but wrong assumptions about patient needs, behaviours or tolerance for clinical trial settings. A fairly recent one is the discontinuation of the inhaled insulin product Exubera, marketed by Pfizer. Many elements combined to make the uptake of this new form of insulin so slow; the inhaler device was large, and there were patient concerns about the predictability of the dose of insulin that would be provided. Despite successful clinical programs that convinced regulators of its efficacy and safety, payers and some patients were less convinced [10].

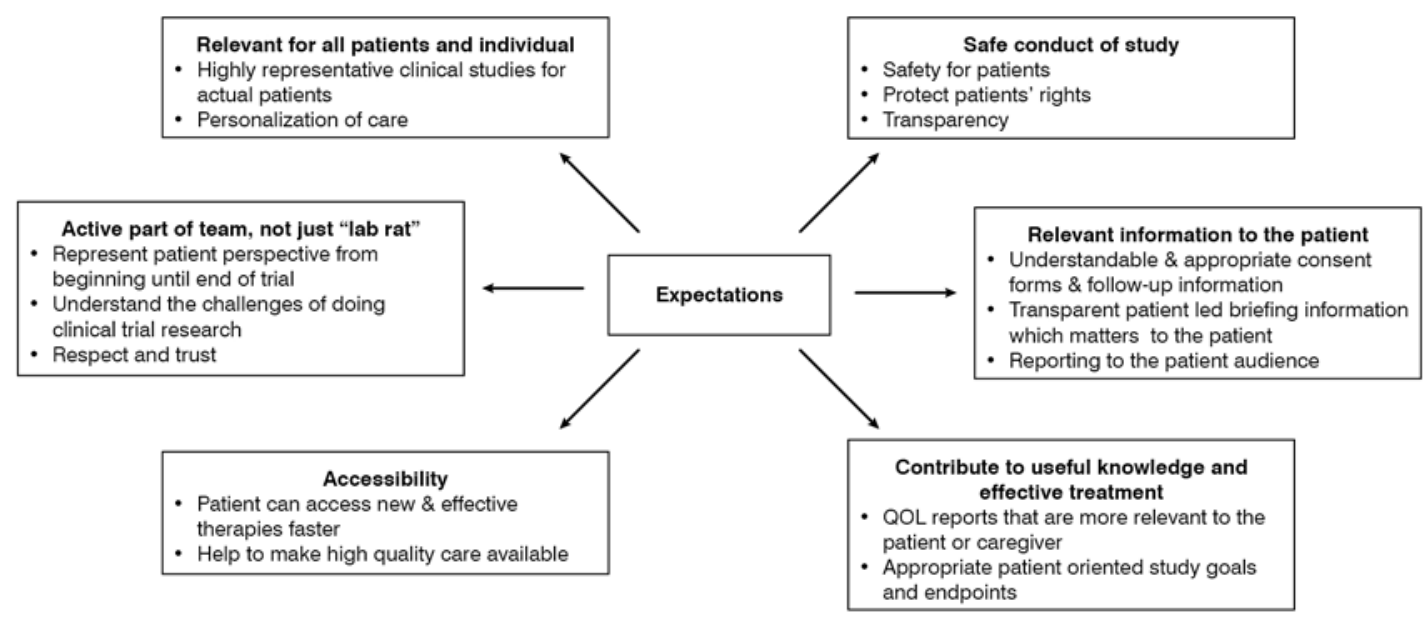

Figure 1. Summary of expectations from patients being actively involved in clinical research as reported in a survey of 40 patient advocates in 2014 [11] 
So, the insights from patients can be critical for the successful adoption of innovations. How do current patient advocates see the need for being involved in research and development? In 2014, we asked a group of 40 patient advocates representing different disease areas and different geographies about their expectations and viewpoints concerning patient involvement in the development of medical innovation [11]. The majority wanted to see a higher involvement of patients in the entire process of clinical research and in any research with impact on clinical decision making, listing or reimbursement decisions. Many of them had experiences originating from formal (e.g. HTA process), informal (e.g. lobbying), or destructive levels (e.g., litigation) of engagement. The participants identified a long list of expected improvements through PPI, which can be summarized into six clusters as shown in in Figure 1.

One of the conclusions of our survey in 2014 was that best practices need to be developed urgently across the development pathway to ensure high quality patient participation. This is still a valid conclusion in 2016. Meanwhile, many organisations are striving to develop such standards by collaborating across stakeholder groups, by creating pilot programs for clinical research development, by involving patients and citizens in the decision-making on adoption and reimbursement for new technologies, and by evaluating the impact of such involvement across all activities. Several studies have started to evaluate the impact of PPI in early research, in medicines development or in reimbursement decisions [12-14]. It should be added that evaluation of impact and experiences in combination with improvement mechanisms are core elements of developing effective PPI processes over the next years.

Critiques may say that not every patient is in the position or willing to become part of the innovation or decision process [15]. While this is probably true, there is no reason to exclude those who are willing to participate and contribute. They can provide valuable insights in order to make healthcare and medical research more relevant to patients. In fact, there are many examples, where patients or their caregivers themselves are prioritizing, financing, or organizing innovation such as the Téléthon movement in France which is supporting impressive research activities purely driven by PPI [16]. In addition, there are many examples of patient organisations actively surveying patients for their experiences with their therapies in ways and words, which are relevant to them (patient based evidence) $[17,18]$. Thus, patients have already learned to speak the fully differentiated language of innovation and will not be treated only as subjects of research. The rest of us should listen, learn and take action.

\section{REFERENCES}

1. Balz V, Klöppel U, Hulverscheidt M, et al. Arzneimittel des 20. Jahrhunderts: Historische Skizzen von Lebertran bis Contergan (Science Studies) (Paperback)(German) - Common. Transcript Verlag, 2009

2. Crimp D. Before Occupy: How AIDS Activists Seized Control of the FDA in 1988. The Atlantic 2011. Available at: http:/www.theatlantic.com/health/archive/2011/12/before-occupy-how-aids-activists-seized-control-of-the-fdain-1988/249302/ (Last accessed March 2016)

3. Rosenberg W, Donald A. Evidence based medicine: an approach to clinical problem-solving. BMJ 1995; 310: 11226; http://dx.doi.org/10.1136/bmj.310.6987.1122

4. Henshall C, Koch P, von Below GC, et al. Health Technology Assessment in Policy and Practice. Int J Technol Assess Health Care 2002; 18: 447-55; http://dx.doi.org/10.1017/S0266462302000302

5. Cuche M, Beckerman R, Chowdhury CA, et al. Early dialogue with health technology assessment bodies: a European perspective. Int J Technol Assess Health Care 2014; 30: 571-8; http://dx.doi.org/10.1017/S0266462314000713

6. EMA. European Medicines Agency - Patients and consumers. Available at: http://www.ema.europa.eu/ema/index. jsp?curl=pages/partners_and_networks/general/general_content_000317.jsp\&mid=WC0b01ac058003500c (Last accessed March 2016)

7. Hoos A, Anderson J, Boutin M, et al. Partnering With Patients in the Development and Lifecycle of Medicines: A Call for Action. Ther Innov Regul Sci 2015; 49: 929-39; http://dx.doi.org/10.1177/2168479015580384

8. EULAR Secretariat, Switzerland. EULAR Standing Committee of PARE. Available at: http://www.eular.org/myUploadData/files/PARE_Values_Principles_web.pdf(Last accessed March 2016) 
9. Pushparajah D, Geissler J, Westergaard N. EUPATI: Collaborating between patients, academia and industry to champion the informed patient in medicines research and development. J Med Dev Sci 2015; 1 Available at http:// jmds.whioce.com/index.php/journal-of-medicines-development/article/view/01011 (Last accessed March 2016)

10. Forst T, Hohberg C, Schöndorf T, et al. Time-action profile and patient assessment of inhaled insulin via the Exubera device in comparison with subcutaneously injected insulin aspart via the FlexPen device. Diabetes Technol Ther 2009; 11: 87-92; http://dx.doi.org/10.1089/dia.2008.0039

11. Holtorf AP, Palacios D, Brixner DI. The Role of Patients in Clinical Research and Evidence Based Decision Making as Reported Via a Survey of Patient Advocates. Value in Health 2014; 17: A435; http://dx.doi.org/10.1016/j. jval.2014.08.1119

12. Buck D, Gamble C, Dudley L, et al. From plans to actions in patient and public involvement: qualitative study of documented plans and the accounts of researchers and patients sampled from a cohort of clinical trials. BMJ Open 2014; 4: e006400; http://dx.doi.org/10.1136/bmjopen-2014-006400

13. Gamble C, Dudley L, Allam A, et al. An evidence base to optimise methods for involving patient and public contributors in clinical trials: a mixed-methods study. Southampton (UK): NIHR Journals Library, 2015

14. Dudley L, Gamble C, Preston J, et al. What Difference Does Patient and Public Involvement Make and What Are Its Pathways to Impact? Qualitative Study of Patients and Researchers from a Cohort of Randomised Clinical Trials. PLoS ONE 2015; 10: e0128817; http://dx.doi.org/10.1371/journal.pone.0128817

15. Carvel D. Patient-partners may be political correctness gone too far. BMJ 1999; 319: 783-4

16. AFM-Téléthon. Available at: http://www.afm-telethon.fr/home (Last accessed March 2016)

17. Dunkle M, Pines W, Saltonstall PL. Advocacy groups and their role in rare diseases research. Adv Exp Med Biol 2010; 686: 515-25; http://dx.doi.org/10.1007/978-90-481-9485-8_28

18. Staniszewska S, Crowe S, Badenoch D, et al. The PRIME project: developing a patient evidence-base. Health Expect 2010; 13: 312-22; http://dx.doi.org/10.1111/j.1369-7625.2010.00590.x 